To appear in The Oxford Handbook of Grammatical Number, edited by Patricia Cabredo Hofherr and Jenny Doetjes.

Individuation: Number marking languages vs. classifier languages

\title{
Pierina Cheung
}

Nanyang Technological University, Singapore

Corresponding Author:

Pierina Cheung

Centre for Research in Child Development

National Institute of Education

Nanyang Technological University, Singapore

Email: cheung.pierina@gmail.com 


\section{Individuation: Number marking languages vs. classifier languages}

\section{Introduction}

We know what counts as one book or one hippo when asked "how many," because entities such as books and hippos are construed as individuals. The same question, however, cannot be asked of non-solid substances such as water and mustard, because it is not clear what counts as one water. This is not only a conceptual distinction between objects and substances, but also a distinction reflected in linguistic structure. In Indo-European languages such as English and Spanish, countable individuals are typically labelled by count nouns, which can occur in both singular and plural forms (e.g., hippo vs. hippos), and non-individuated substances are typically labelled by mass nouns, which cannot be pluralized (e.g., *waters) and require measure words for quantification (e.g., two buckets of water). Languages with mass-count syntax are thus called number marking languages. However, not all languages have mass-count syntax. Classifier languages, which characterize most Asian languages (e.g., Mandarin Chinese, Japanese) and Mayan languages (e.g., Yucatec, Tzotzil), do not make a syntactic distinction between mass and count nouns. Nouns in classifier languages cannot co-occur directly with numerals $\left({ }^{*}\right.$ san $b i=$ 'three pen'), and require classifiers for counting (e.g., san zhi bi, which means three pens, is literally translated to 'three stick pen'), similar to the use of measure words in English mass nouns. Unlike English, there is no obligatory plural marking in classifier languages (for details, see Chapter 2).

For decades, psychologists, linguists, and philosophers alike have wondered whether learning a number marking language affects how we construe entities in the world (e.g., Bloom and Keil 2001; Bowerman and Levinson 2001; Imai and Gentner, 1997; Li, Dunham, and Carey, 2009; Lucy, 1992; Macnamara 1986; Quine, 1960; Whorf, 1956). Is the distinction between 
individuals and non-individuals available to speakers of all languages, prior to language learning, or is it a product of acquiring a number marking language?

In his pioneering work, Benjamin Lee Whorf (1956) argues that the languages we speak influence how we think. On the strong version of the Whorfian hypothesis, speakers cannot conceptualize entities as individuals or non-individuals without mass-count syntax (see Quine, 1960, 1969, for a similar proposal), but recent studies have ruled this out, because even prelinguistic infants can track individual entities in space and time (e.g., Spelke, Kestenbaum, Simons, and Wein 1995; Xu and Carey 1996), suggesting that prior to language learning, infants have the capacity for representing and individuating objects. In recent years, the focus has shifted to investigating the possibility that language affects the criteria for what counts as an individual. In this chapter, we discuss two hypotheses on the role of number marking languages on the construal of individual entities - a weak version of the Whorfian hypothesis and the lexical statistics hypothesis (non-Whorfian) - and present experimental findings from cross-linguistic comparisons and developmental psychology that help tease them apart.

\section{Hypotheses on the role of number marking languages on object-substance construal}

\subsection{Weak Whorfian hypothesis}

Although the strong version of the Whorfian hypothesis has fallen out of favour, recent years have observed an increased attention to investigating the weak Whorfian hypothesis, which draws on the notion of an individuation continuum, with entities that are highly individuable such as humans and animals on one end and entities that are non-individuable such as non-solid substances on the other end (Lucy 1992; Gentner and Boroditsky 2001). On this hypothesis, different languages partition this continuum differently, and language-specific structures could 
affect the criteria for determining whether an entity is an individual object (Lucy 1992; Imai and Gentner 1997). For example, English refers to inanimate objects such as forks, cups, and tables using count syntax, and it thus grammatically treat objects as individuated, whereas Yucatec Mayan does not, because it lacks obligatory plural morphology for objects. Furthermore, Lucy (1992) argues that a quantificational unit - in the form of object shape - is presupposed in English count nouns (e.g., English-speakers extend nouns such as 'fork' to fork-shaped entities; Landau, Smith and Jones 1988, 1992), and no such unit is presupposed in mass nouns. Given these reasons, "English lexical structure routinely draws attention to shape, Yucatec lexical structure routinely draws attention to material" (Lucy 1992: 89). To specify quantification in classifier languages such as Yucatec Mayan and Mandarin Chinese, classifiers are needed (see also Borer 2005). For example, the Yucatec Mayan word for banana (ha'as) does not denote a kind of individual by default, but is consistent with meanings such as "banana-fruit", "bananaleaf", "banana-bunch”, and "banana-stuff”. According to Lucy, speakers of Yucatec can distinguish these meanings via the use of classifiers. In each of the following cases, the noun ha'as has a different meaning depending on the classifier used (Lucy 1992: 74). Lucy claims that, without a classifier, $h a$ 'as has a non-individuated meaning.

(1) a. 'un-p'éel há'as 'one/a 3-dimens. banana (e.g., the fruit)'

b. 'un-wáal há'as 'one/a 2-dimens. banana (i.e., the leaf)'

c. 'un-kúul há'as 'one/a planted banana (i.e., the tree)' 
Imai and Gentner (1997) offer a similar view, but place heavier weight on perceptual features (e.g., perceptual complexity) in determining the individual status of an entity. They argue that the effects of linguistic structure lie predominantly on entities that fall in the middle of the continuum, such as simple-shaped objects, which are ambiguous with respect to categorization. However, complex-shaped objects can be construed as individuals, and nouns for these objects can thus have individuated meanings even without classifiers.

Regardless of the role of perceptual features, the weak Whorfian hypothesis posits that, depending on one's language, speakers develop distinct preferences for attending to the shape or material of an entity, and cross-linguistic differences in object construals should be observed across different types of tasks. As we will show in detail below (section 3), both Lucy and Imai and Gentner offer experimental evidence for the existence of the predicted differences.

\subsection{Lexical statistics hypothesis}

A more recent line of research casts doubt on the weak Whorfian hypothesis and raises questions about whether cross-linguistic differences in object construals truly reflect differences in nonlinguistic thought or whether they reflect language-on-language effects (Fisher and Gleitman 2002; Gleitman and Papafragou 2005; Li et al. 2009). On this proposal, the crosslinguistic differences observed in previous studies are due to lexical statistics. In number marking languages, count nouns and mass nouns have different distributional statistics, with count nouns being more frequent than mass nouns (Samuelson and Smith 1999). Thus, in tasks that require participants to interpret familiar or novel nouns, the distributional statistics of lexical items in their own language could affect their judgments. For example, English speakers may interpret 
novel nouns as count nouns because count nouns are more frequent than mass nouns, and since count nouns typically refer to individuals, English speakers may interpret novel nouns as referring to objects rather than substances. Even in verbal tasks that use neutral syntax (e.g., Look at this), participants may draw on their probabilistic expectations of lexical items to interpret deictic terms such as this. The fact that speakers from different language groups have different information and expectations about lexical items that are used in the experiments may explain the cross-linguistic differences found in previous studies.

The lexical statistics hypothesis posits that cross-linguistic differences should be most salient in lexical tasks such as the word extension task or tasks that require participants to interpret the meaning of ambiguous lexical items, but they should NOT be observed across different types of tasks.

\section{Studies on the role of number marking languages on object-substance construal}

\subsection{Similarity judgment and object sorting tasks}

Using a series of object classification tasks, Lucy (1992) provided some of the earliest evidence that speakers of number marking languages such as English perceive objects differently from those who speak classifier languages such as Yucatec. In one experiment, he examined whether speakers of English and Yucatec use different criteria to judge the similarity of objects. He first showed a target entity to participants (e.g., cardboard box), followed by two alternate objects, one that matched the target in shape but not in material (e.g., plastic box), and another that matched the target in material but not in shape (e.g., piece of cardboard). Participants were then asked to choose one that was "most like" the target entity. He found that English-speaking 
adults showed a strong preference for the shape-matched alternate while the Yucatec speakers preferred the material-matched alternate, suggesting an effect of language on object construals.

However, there are alternative explanations for the observed cross-linguistic difference.

First, the use of familiar objects may have prompted participants to judge the similarity of objects based on their shared labels. Although the experimenter never labeled the target object, participants could be choosing the alternate based on the name of an object (e.g., choosing a plastic box as being similar to a cardboard box because they can both be labelled as a box). While this is still an effect of language, it is not an effect due to mass-count syntax but an effect of labeling. And this may be especially prevalent among English speakers who spend more time labeling objects than speakers from other cultures (Fernald and Morikawa, 1993; Tardif, Shatz and Naigles 1997). To address this alternative explanation, Lucy and Gaskins (2001) first presented English and Yucatec speakers with eight objects, one at a time, and asked them to sort the objects into two groups; then, they presented participants with the ninth object, which was the target object, and examined how they sorted it. For the first eight objects, they equated the number of objects that can be sorted by shape (tube-shaped objects) and the number of objects that can be sorted by material (cardboard-like material). Participants were thus primed to sort a collection of objects based on either shape or material, minimizing the likelihood that they recruited the labeling strategy to sort the target object, which shared the same shape and material as previous objects (toilet paper core). Lucy and Gaskins (2001) found that English speakers sorted the last object primarily on the basis of shape and Yucatec speakers primarily on the basis of material, thus extending the cross-linguistic difference in an object sorting task and ruling out the effect of labelling in the original experiment. 
A second factor that could have affected the participants' judgments in the original experiment is shared functionality of objects, given that objects that share the same shape typically have similar functions. For example, participants could be choosing a plastic box over a piece of cardboard as being similar to a cardboard box because both the plastic box and the cardboard box can hold objects. Thus, choosing a shape-matched alternate may in fact be explained by shared functionality. Using the same similarity judgment paradigm, Lucy and Gaskins manipulated the function of object stimuli in a follow-up study and found that English speakers continued to choose the shape match more likely than Yucatec speakers.

These follow-up experiments suggest that functionality and object labeling cannot explain the differences between how English and Yucatec speakers judged the similarity of objects, but it remains a possibility that the differences are non-linguistic in nature. For example, in addition to linguistic differences, English and Yucatec speakers differ on a number of cultural factors, such as level of education and experiences with artifacts. Yucatec speakers were subsistence farmers with limited experience with artifacts relative to college undergraduate students from North America, and these differences may explain the way English and Yucatec speakers judge and sort objects. To control for cultural factors, Mazuka and Friedman (2000) tested Japanese speakers who have similar levels of education and exposure to artifacts as English speakers, but they have failed to replicate previous findings on the similarity judgment task. While this might suggest that Lucy's original findings were specific to Yucatec speakers, the cross-linguistic differences have been replicated in another major study using a different paradigm (Imai and Gentner, 1997; see also Li, Dunham and Carey 2009, who further replicated Imai and Gentner's findings), and this study was conducted with Japanese speakers, suggesting that the cross-linguistic differences are likely robust. We review this major study below. 


\subsection{The word extension task}

Imai and Gentner (1997) took a different approach in exploring the role of number marking languages on individuation: they used a word extension task inspired by Soja, Carey and Spelke (1991) and included young children between the ages of 2 and 4 . Their primary question was whether the acquisition of count syntax causes children to develop a distinct preference for shape. As such, they compared adults to children as young as 2 who had little to no knowledge of count syntax (Gordon 1985, 1988; Soja 1992). Extending Lucy’s work, they tested whether there are cross-linguistic differences in how English and Japanese speakers extend novel words using the word extension paradigm.

In this paradigm, the experimenters first labeled a target entity with a novel word (e.g., $d a x$ ), and the novel word was embedded in neutral syntax that is ambiguous between mass and count interpretations in English (e.g., the demonstrative this in Look at this dax). They then showed participants two alternates, one that matched the standard entity by shape but not in material (shape-matched alternate) and another that matched the entity by material but not in shape (material-matched alternate), and asked participants which one of the two alternates was the dax (e.g., Can you point to the tray that also has the dax on it?)

To investigate whether and how learning a number marking language influences object construals, they used a range of target entities that fall on the individuation continuum. On some trials, the target entity was a kind of nonsolid substance (e.g., portion of sand in an S shape) and on other trials, it was a kind of solid object, which were further divided into complex-shaped solid objects (e.g., lemon juicer) and simple-shaped solid objects (e.g., cork pyramid).

If learning a number marking language affects the criteria for construing an entity as an object, then English- and Japanese-speaking children should show differences in how they extend 
novel words. In particular, English-speaking children should extend novel words for object kinds on the basis of shape (i.e., choosing the shape-matched alternate) and novel words for substance kinds on the basis of material (i.e., choosing the material-matched alternate), whereas Japanesespeaking children should make no distinction across different types of entities (i.e., choosing randomly between the shape- or material-matched alternate). However, if the ontological distinction between objects and substances is available to speakers of all languages, then even the youngest children - i.e., 2-year-olds - should extend novel words on the basis of the nature of the entities. That is, they should extend novel words for object kinds to other solid objects that share the same shape, and novel words for substance kinds to other nonsolid substances on the basis of the same substance, regardless of whether they are learning English or Japanese.

Imai and Gentner (1997) found a mixed pattern of results. First, they found crosslinguistic similarities. Even at the youngest age, both English- and Japanese-speaking children (and adults) extended complex objects by shape at least $80 \%$ of the time. They also distinguished between complex objects and nonsolid substances, and were less likely to extend by shape for substances than complex objects. Second, they found cross-linguistic differences. On simpleshaped trials, at each age group, English-speaking participants chose the shape-matched more often than their Japanese-speaking counterparts, who chose randomly between the shape-matched alternate and the material-matched alternate.

These results suggest that regardless of language type, starting at age 2, children can distinguish between complex objects and substances (see also Soja et al. 1991; section 3.5 below), but the results on simple-shaped objects also suggest that these distinctions are malleable and that speaking specific languages allow its speakers to mark the individuation boundary differently. In their own words, "Japanese speakers and English speakers appeared to use 
different criteria in determining the class membership for a given instance, suggesting that they have a different representation for, or at least a different boundary between, individuals and nonindividuals" (p. 195; see also Imai and Mazuka 2003, 2007, for similar findings).

\subsection{Interpretations of the cross-linguistic differences}

These findings can be interpreted as providing support for the weak Whorfian hypothesis. Speakers of English are more likely than speakers of Yucatec to judge the similarity of objects based on shape (Lucy 1992), and are more likely than speakers of Japanese to extend novel words on the basis of shape for simple-shaped objects (Imai and Gentner, 1997). However, the current set of findings is also consistent with the lexical statistics hypothesis, which argues that the crosslinguistic differences are, in fact, effects of lexical statistics on language processing. For example, despite the use of neutral syntax in the word extension task (the dax) or the use of deictic terms in the similarity judgment task (Look at this), speakers still have to interpret the intended meaning of the lexical items such as the or this, and how speakers process the intended meaning may very well be affected by the statistical distribution of noun types in one's language.

\subsection{Object rating task and the lexical statistics hypothesis}

To address this possibility, $\mathrm{Li}$ and colleagues used an object rating task in which participants were explicitly asked whether an entity is an instance of an object kind or substance kind ("Look at each entity and rate your likelihood of seeing that entity as an object or a substance"). They also provided participants with examples of what they meant by "object" and "substance". This design minimizes the need to engage in pragmatic reasoning and makes clear what is required of the participants; participants can use any criteria they deem necessary to 
determine the individual status of an entity. Using this object rating task with novel entities, Li et al. compared adult speakers of English to Japanese and Mandarin monolinguals. They reasoned that if linguistic differences between classifier languages and number marking languages do indeed affect the underlying object construals of speakers by making certain features more salient, then English speakers should be more likely to construe novel entities as being an instance of an object kind than Mandarin speakers.

Contrary to this prediction, $\mathrm{Li}$ and colleagues found that Japanese and Mandarin speakers did not differ from English speakers in how they rated the novel entities (see also Barner, Inagaki and Li 2009; Colunga and Smith 2005; Sandhofer, Smith, and Luo 2000). All speakers take into account factors such as solidity and functionality (whether the novel entity serves a particular function). Ratings across speakers of different language groups were highly correlated, suggesting that they draw on the same stimulus properties in judging whether something is an object kind or a substance kind. Note that these are participants with years of experience with their native language, and yet, there was no effect of language in this simple object-rating task. These findings suggest that previous cross-linguistic differences are best explained by the linguistic nature of previous tasks.

Two other pieces of findings provide further support for the lexical statistics hypothesis. First, using a word extension task with a carefully constructed set of stimuli that crossed shape complexity with shape-based functionality, Li et al. replicated the cross-linguistic differences, with English speakers extending novel words by shape more likely than Mandarin and Japanese speakers. Participants in this study were recruited from the same population as those in the object rating task, thus ruling out population differences as an explanation, and highlighting task differences - i.e., whether participants have to interpret word meanings - as an important factor. 
Second, in the word extension task, they found that shape complexity and functionality affect English, Mandarin, and Japanese speakers' object construals to a similar extent. Across all three language groups, entities with complex shapes and those with shape-dependent functions received more shape-based responses. This provides convergent evidence that stimulus properties have a similar effect on speakers learning classifier languages and those learning number marking languages.

The evidence reviewed thus far focuses on how adult participants construe objects, but how do preferences for object construals develop? The lexical statistics hypothesis predicts that (1) initially, children from different language groups should construe entities similarly, and (2) any developmental changes with respect to shape-based judgments should be observed in children learning a number marking language, at an age when children can access the distributional statistics of count and mass nouns. In the following section, we review developmental findings that bear on these two predictions of the lexical statistics hypothesis.

\subsection{Further support for the lexical statistics hypothesis: developmental work}

\subsubsection{Universal ontology}

Previous studies have documented cross-linguistic similarities on object construals early in development. For example, Imai and Gentner (1997) found that Japanese-speaking 2-year-olds and English-speaking 2-year-olds both chose the shape-matched alternate when shown complex objects, and the material-matched alternate when shown nonsolid substances. This pattern was first documented in a classic study by Soja et al. (1991) with English-speaking 2-year-olds, and has now been shown in three different laboratories with different language groups (e.g., Imai and 
Gentner 1997; Li et al. 2009), providing strong evidence for a universal ontology for objects and substances.

Several other pieces of evidence from developmental psychology provide further support that the ontological distinction between objects and substances appears early in development. First, studies have shown that as young as $4 \frac{1}{2}$ months, infants can use spatiotemporal criteria to individuate solid, bounded, and coherent objects (Mehler and Fox 1985; Spelke et al. 1995; Spelke, 1985, 1990; Xu and Carey 1996; see also Wynn 1992; Uller et al. 1999). This line of research suggests that the concept of object is not a product of language learning, but is available prior to acquiring count syntax. Second, prelinguistic infants track objects and substances differently. In one study, 8-month-olds saw one pile of sand poured onto a stage; the stage was covered and infants saw more sand poured onto the stage (Huntley-Fenner et al. 2002; see also Rosenberg and Carey 2009). They found that infants were not surprised at the unexpected outcome of one pile of sand. However, when shown a coherent object in the form of a pile of sand, infants were surprised when only one object appeared but not surprised when two objects appeared. The failure in tracking substances and the success in tracking objects suggest that infants draw on different cues to predict the behaviour of objects and substances (see also Gao, Levine, and Huttenlocher 2000; Hespos et al. 2012, for evidence that infants can indeed track substance kinds). In more recent studies, Hespos and colleagues have further shown that by 5 months, infants use cues of movement and penetrability to discriminate nonsolid substances from objects (Hespos, Ferry, and Rips 2009; Hespos et al. 2016; for reviews, see Hespos and van Marle 2012; Rips and Hespos 2015). Taken together, these studies provide evidence for an early development of ontological categories of objects and substances. 


\subsubsection{Developmental changes}

According to the lexical statistics hypothesis, shape-based categorization should be higher among English learners than learners of classifier languages, because only English speakers can draw on the distributions of count nouns and mass nouns to decide whether to treat a novel word as a count noun. Furthermore, developmental changes of shape-based categorization should be observed at a point in the developmental period that correlates with the acquisition of mass-count syntax.

With regard to which language group demonstrates more shape-based judgments over time, several studies have shown that English-speaking children are the ones who have the clearest preference for shape-based judgments. For example, Imai and Gentner (1997) found that English-speaking children are more likely than Japanese-speaking children to choose the shape matches for simple objects in a word extension task. Li and colleagues reported similar findings when comparing English-speaking children to Mandarin- and Japanese-speaking children.

Nevertheless, studies differ with respect to when cross-linguistic differences in shapebased categorization are observed. For example, Imai and Gentner (1997) found that by age 2, English-speaking children are more likely than Japanese-speaking children to choose the shape matches for simple objects. This early emergence of shape-based categorization contrasts the finding of Li and colleagues, who found that cross-linguistic differences emerge at around age 5 (see also Subrahmanyam and Chen 2006, Gathercole and Min 1997, Lucy and Gaskins, 2001, 2003, for findings that support a later emergence). The late emergence of the cross-linguistic differences is more consistent with studies that show English-speaking children acquire the masscount syntax at or after age 3 (Gordon 1985, 1988). On the lexical statistics hypothesis (and also the weak Whorfian hypothesis), it is unlikely that cross-linguistic differences would be observed 
prior to the acquisition of mass-count syntax. Collectively, these results suggest that Englishspeaking children likely demonstrate a bias towards shape-based categorization sometime after they acquire mass-count syntax, at around ages 4 to 5, whereas Mandarin- or Japanese-speaking children show no such bias.

Overall, these results are in line with the lexical statistics hypothesis, with one caveat. Studies from multiple laboratories have also found that children learning classifier languages show more material-based categorization, a pattern of results not predicted by the lexical statistics hypothesis. For example, between the ages of 2 and 5, children learning classifier languages show a decrease in shape match on the word extension task (and thus an increase in material matches; Imai and Gentner 1997; Li et al. 2009). This is also shown in Lucy and Gaskins (2001, 2003), though with slightly older children, at around ages 7 to 9, using a similarity judgment task. Does the increase in material-based categorization suggest that nouns in classifier languages denote substances and thus speakers of those languages may develop a preference for the material nature of objects? Not necessarily. First, the object rating studies have shown that nouns in classifier languages are not more likely to refer to substances than nouns in number marking languages ( $\mathrm{Li}$ et al. 2009; Barner et al. 2009). Second, the claim that speakers of classifier languages develop different preferences for construing objects because of a lack of mass-count distinction is challenged by recent studies that suggest that the distinction is not entirely absent in classifier languages. For example, in a recent study, children demonstrate sensitivity to how some classifiers pick out individuals, and to how some classifiers select over portions of substances and collections of individuals (Li, Barner and Huang 2009; see also Chien, Lust and Chiang, 2003 for similar results). These results suggest that classifier languages make a mass-count distinction at the lexical level (see also Doetjes 2012). 
What, then, can explain the increase in material matches in children learning classifier languages? Li et al. propose that the increase in material-based categorization is, in fact, present in both speakers of classifier languages and those of number marking languages. This is driven by an increased sensitivity towards material that occurs during the preschool period. For example, children begin to acquire words denoting solid and nonsolid substances starting at ages 3 to 4 (e.g., Dickinson 1988; Prasada 1993). However, knowledge of the distribution of count nouns may have dampened the material sensitivity among English-speaking children. Children learning Japanese or Mandarin, on the other hand, do not have knowledge of count syntax to offset the general bias towards material. Specifically, Li and colleagues argue that the developmental changes "may reflect two interacting factors: an increase in salience of material with age (in both cultures) together with a language-driven effect of count syntax distribution in English" (Li et al. 2009: 22).

\section{Summary}

Since Lucy (1992), there has been considerable progress in investigating the role of number marking languages on object individuation. Recent studies have provided strong evidence that the cross-linguistic differences first documented by Lucy (1992) are best explained as a language-on-language effect ( $\mathrm{Li}$ et al. 2009; see also Barner et al. 2009; Fisher and Gleitman 2002; Gleitman and Papafragou 2005). When shown an ambiguous entity that could be construed as an object or substance, English speakers draw on their knowledge of the distribution of count and mass nouns, and given the high proportion of count nouns in their language, English speakers infer that the ambiguous entity is likely an object labeled by a count noun. Mandarin or Japanese speakers do not have access to such linguistic information, and thus do not show a bias towards 
shape-based categorization. Furthermore, in the past two decades, infant studies on object and substance representations have shown that the object-substance distinction is present very early in development, supporting a universal ontology account of individuation (Hespos and van Marle 2012; Rips and Hespos 2015; Soja et al. 1991). Together, these results provide support for the lexical statistics hypothesis, and suggest that speakers of number marking languages do not construe objects differently from those of classifier languages. 
References

Barner, David, Shunji Inagaki, and Peggy Li (2009). 'Language, thought, and real nouns', Cognition 111: 329-344.

Bloom, Paul, and Frank Keil (2001). 'Thinking through language', Mind and Language 16: 351367.

Bowerman, Melissa, and Stephen Levinson (2001). Language acquisition and conceptual development. Cambridge: Cambridge University Press.

Borer, Hagit (2005). Structuring sense. Oxford, UK: Oxford University Press.

Chien, Yu-Chin, Barbara Lust, and Chi-Pang Chiang (2003). 'Chinese children's comprehension of count classifiers and mass-classifiers', Journal of East Asian Linguistics 12: 91-120.

Colunga, Eliana, and Linda B Smith (2005). 'From the lexicon to expectations about kinds: A role for associative learning', Psychological Review 112: 347-382.

Dickinson, David K (1988). 'Learning names for materials: Factors constraining and limiting hypotheses about word meaning', Cognitive Development 3: 15-35.

Doetjes, Jenny (2012). 'Count/mass distinctions across languages,' in Claudia Maienborn, Klaus von Heusinger and Paul Portner (eds), Semantics: an international handbook of natural language meaning, part III. Berlin: De Gruyter, 2559-2580.

Fernald, Anne, and H. Morikawa (1993). 'Common themes and cultural variations in Japanese and American mothers' speech to infants', Child Development 64: 637 - 656.

Fisher, Cynthia, and Lila Gleitman (2002). 'Breaking the linguistic code: Current issues in early language learning', in Hal Pashler and Randy Gallistel (eds), Stevens' Handbook of Experimental Psychology, Learning and motivation Vol. $3^{\text {rd }}$. New York: Wiley, 445-496.

Gao, Fan, Susan Levine, and Jannelle Huttenlocher (2000). 'What do infants know about continuous quantity', Journal of Experimental Child Psychology 77: 20-29.

Gathercole, Virginia M, and Haesik Min (1997). 'Word meaning biases or language-specific effects? Evidence from English, Spanish, and Korean', First Language 17:31-56.

Gordon, Peter (1985). 'Evaluating the semantic categories hypothesis: The case of the count/mass distinction', Cognition 20: 209-242.

Gordon, Peter (1988). 'Count/mass category acquisition: Distributional distinctions in children's speech', Journal of Child Language 15: 109-128.

Hespos, Susan, Alissa Ferry, and Lance Rips (2009). 'Five-month-old infants have different expectations for solids and liquids', Psychological Science 20: 603-611.

Hespos, Susan, Alissa Ferry, Erin Anderson, Emily Hollenbeck, and Lance Rips (2016). 'Fivemonth-old infants have general knowledge of how nonsolid substances behave and intact', Psychological Science 27: 244-256.

Hespos, Susan, Begum Dora, Lance Rips, and Stella Christie (2012). 'Infants make quantity discriminations for substances', Child Development 83: 554-567.

Hespos, Susan, and Kristy van Marle (2012). 'Physics for infants: Characterizing the origins of knowledge about objects, substances, and number', Wiley Interdisciplinary Reviews:

Cognitive Science 3: 19-27.

Huntley-Fenner, Gavin, Susan Carey, and A Solimando (2002). 'Objects are individuals but stuff doesn't count: Perceived rigidity and cohesiveness influence infants' representations of small groups of discrete entities, Cognition 85: 203-221.

Imai, Mutsumi, and Dedre Gentner (1997). 'A cross-linguistic study of early word meaning: universal ontology and linguistic influence', Cognition 62: 169-200. 
Imai, Mutsumi, and Reiko Mazuka (2003). 'Re-evaluation of linguistic relativity: Languagespecific categories and the role of universal ontological knowledge in the construal of individuation', in Dedre Gentner and Susan Goldin-Meadow (eds), Language in Mind: Advances in the issues of language and thought. Cambridge, MA: MIT Press, 429-464.

Imai, Mutsumi, and Reiko Mazuka (2007). 'Revisiting language universals and linguistic relativity: language-relative construal of individuation constrained by universal ontology', Cognitive Science 31: 385-414.

Landau, Barabara, Linda B. Smith, and S. Jones (1988). 'The importance of shape in early lexical learning', Cognitive Development 3: 299-321.

Landau, Barabara, Linda B. Smith, and S. Jones (1992). 'Syntactic context and the shape bias in children's and adults' lexical learning', Journal of Memory \& Language 31: 807-825.

Li, Peggy, Yarrow Dunham, and Susan Carey (2009). 'Of substance: The nature of language effects on entity construal', Cognitive Psychology 58: 487-524.

Li, Peggy, David Barner, and Becky Huang (2009). 'Classifiers as count syntax: individuation and measurement in the acquisition of Mandarin Chinese', Language Learning and Development 4: 1-42.

Lucy, John A (1992). Grammatical categories and cognition. Cambridge, UK: Cambridge University Press.

Lucy, John A, and Suzanne Gaskins (2001). 'Grammatical categories and the development of classification preferences: A comparative approach', in Melissa Bowerman and Steven Levinson (eds), Language acquisition and conceptual development. Cambridge, UK: Cambridge University Press, 257-283.

Lucy, John A, and Suzanne Gaskins (2003). 'Interaction of language type and referent type in the development of nonverbal classification preferences', in Dedre Gentner and Susan GoldinMeadow (eds), Language in mind: Advances in the issues of language and thought. Cambridge, MA: MIT, 465-492.

Macnamara, John (1986). ' A border dispute', Cambridge, MA: MIT Press.

Mazuka, Reiko, and Ronald Friedman (2000). 'Linguistic relativity in Japanese and English: Is language the primary determinant in object classification?' Journal of East Asian Linguistics 9: 353-377.

Mehler, Jacques, and Robin Fox (1985). Neonate cognition: Beyond the blooming buzzing confusion. Hillsdale, N.J.: L Erlbaum Associates.

Quine, W.V.O (1960). Word and object. Cambridge, MA: MIT Press.

Quine, W.V.O (1969). Ontological relativity and other essays. New York: Columbia University Press.

Rips, Lance, and Susan Hespos (2015). 'Divisions of the physical world: Concepts of objects and substances', Psychological Bulletin 141: 786-811.

Rosenberg, Rebecca D, and Susan Carey (2009). 'Infants' reasoning about material entities', in Bruce M Hood and Laurie R Santos (eds), The origins of object knowledge. Oxford University Press.

Prasada, Sandeep (1993). 'Learning names for solid substances: Quantifying solid entities in terms of portions', Cognitive Development 8: 83-104.

Samuelson, Larrisa, and Linda B Smith (1999). 'Early noun vocabularies: Do ontology, category structure and syntax correspond?' Cognition 73: 1-33. 
Sandhofer, Catherine, Linda B. Smith, and Jun Luo (2000). 'Counting nouns and verbs in the input: Differential frequencies, different kinds of learning?' Journal of Child Language 27: 561-585.

Slobin, Dan (1996). 'From thought and language "to" thinking to speaking', in John J Gumperz and Stephen Levinson (eds), Rethinking linguistic relativity. Cambridge: Cambridge University Press, 70-96.

Slobin, Dan I (2003). 'Language and thought online: Cognitive consequences of linguistic relativity', in Dedre Gentner and Susan Goldin-Meadow (eds), Language in mind. Cambridge, MA: MIT Press.

Soja, Nancy N (1992). 'Inferences about the meanings of nouns: The relationship between perception and syntax', Cognitive Development 7: 29-46.

Soja, Nancy N, Susan Carey, and Elizabeth S. Spelke (1991). 'Ontological categories guide young children's inductions of word meaning: Object terms and substance terms', Cognition 38: 179-211.

Spelke, Elizabeth S (1985). 'Perception of unity, persistence, and identity: Thoughts on infants' conceptions of objects', in Jacques Mehler and R Fox (eds), Neonate cognition: Beyond the blooming buzzing confusion. Hillsdale, NJ: Lawrence Erlbaum Associates.

Spelke, Elizabeth S, R. Kestenbaum, D. J. Simons, and D Wein, D (1995). 'Spatio-temporal continuity, smoothness of motion and object identity in infancy', British Journal of Developmental Psychology 13: 113-142.

Spelke, Elizabeth S (1990). 'Principles of object perception', Cognitive Science 14: 29-56.

Subrahmanyam, Kaveri, and Hsin-Hua Nancy Chen (2006). 'A crosslinguistic study of children's noun learning: The case of object and substance words', First Language 26: 141-160.

Tardif, Twila, Marilyn Shatz, and Letitia Naigles (1997). 'Caregiver speech and children's use of nouns versus verbs: A comparison of English, Italian, and Mandarin' Journal of Child Language 24: 535:565.

Uller, Claudia, Susan Carey, Gavin Huntley-Fenner, and Laura Klatt (1999). 'What representations might underlie infant numerical knowledge?' Cognitive Development 14: 136.

Whorf, Benjamin Lee (1956). Language, thought, and reality: Selected writings of Benjamin Lee Whorf. Cambridge, MA: MIT Press.

Wynn, Karen (1992). 'Addition and subtraction by human infants', Nature 358: 749-750.

$\mathrm{Xu}, \mathrm{Fei}$, and Susan Carey (1996). 'Infants' metaphysics: the case of numerical identity', Cognitive Psychology 30: 111-153.

Yoshida, Hanako, and Linda B. Smith (2003). 'Shifting ontological boundaries: How Japaneseand English-speaking children generalize names for animals and artifacts', Developmental Science 6: 1-34. 